\title{
关于建筑工程造价控制与管理分析探讨
}

\author{
王启金 \\ 云南玉溪三建建设集团有限公司，云南 玉溪 653100
}

[摘要] 随着我国建筑工程的快速发展, 企业对于建筑工程的投资也在不断的加大，建筑工程造价控制与管理问题直接关系到 投资方的经济效益和整个建筑行业市场的发展。当前我国在建筑工程造价控制与管理方面与西方国家相比还有一定的差距, 如何解决这些制约因素, 成为广大建筑行业工作人员重点研究和探讨的问题。

[关键词]工程造价管理; 对策; 研究

DOI：10.33142/ec.v3i5.1916 中图分类号: TU723.3 文献标识码：A

\section{Discussion on Cost Control and Management Analysis of Construction Project}

\author{
WANG Qijin
}

Yunnan Yuxi San Jian Group Co., Ltd., Yuxi, Yunnan, 653100, China

\begin{abstract}
With rapid development of construction engineering in China, the investment of enterprises in construction engineering is also increasing. The cost control and management of construction engineering is directly related to economic benefits of investors and development of whole construction industry market. At present, compared with western countries, there is still a certain gap in cost control and management of construction projects in China. How to solve these constraints has become a key research and discussion issue for majority of construction industry staff.
\end{abstract}

Keywords: project cost management; countermeasures; research

\section{引言}

建筑工程项目施工建设过程中, 尤其是造价管理时的至关重要, 通过科学合理的结算审计, 可以促进工程资金的 有效利用, 并且有利于提升工程资金应用安全可靠性。而且在工程成本降低以及工程质量提高等方面, 起到了有效的 促进作用。

\section{1 建筑工程造价的主要职能}

建筑工程造价的职能主要包括评价职能评价职能、调控职能、预测职能及控制职能。评价职能: 通过工程造价可 以评价投资人在本工程项目上投资是否科学、以及在工程建设过程中建设单位的经营管理是否合理 ${ }^{[1]}$ 。调控职能: 由于 有的建设项目的周期超过了一年, 在施工过程中使用的物资存在后期有涨价的可能, 因此建筑工程造价在进行预算时 要预留可能涨价的费用进行调控。预测职能：建筑工程造价一般是在项目前期进行的，需要预测建筑工程后期的各项 工作。控制职能：建筑工程造价是建筑工程的依据，控制着工程的投资及管理。

\section{2 建筑施工工程的现状}

\section{1 造价信息资源不共享}

各地区的工程造价信息都是相对独立的，还没有实现造价信息资源的共享，这给工程造价编制工作带来了很大影 响, 不利于工程造价质量的提高 ${ }^{[2]}$ 。

\section{2 工程设计水平较差}

虽然工程设计是施工前的准备工作, 但是其重要性却不言而喻, 如果工作人员设计水平低, 又缺乏建设施工经验, 那么设计出来的方案就会出现一些漏洞, 不仅会增加实际施工难度, 还会影响工程造价的质量。可以说, 工程设计给 工程造价的影响最大, 如果工程设计较差, 那么就会严重影响着工程施工质量, 更会增加工程造价预算, 所以, 在工 程设计中, 一定要选择高能力的工程设计人才担任这些工作, 最好是选择对实际施工有经验的工作人员, 这是提高工 程造价和工程质量的最重要环节 ${ }^{[3]}$ 。 


\section{3 审计制度不完善}

工程造价审计工作是需要一定的制度来制约的, 这样才能提高工程造价审计质量, 但是, 多数建设单位不仅缺乏 专业人才，更没有完善的审计制度，这让审计监督形同虚设，根本没有发挥出应有的作用。

\section{4 审计人才缺乏}

工程造价是一项专业性很强的学科, 尽管建筑单位都设有工程造价的审计部门, 但是其审计人员却相对贵乏, 尤 其是对于相对复杂的工程造价内容, 根本就做不出准确的判断, 让审计监管工作流于形式, 甚至有时会造成审计出错, 给工程造价带来严重影响, 更有甚者会导致建设施工出错, 进而给企业带来严重的经济损失, 因此, 为了提高工程造 价的质量, 加强审计人才队伍建设, 引进专业的审计人才非常重要。

\section{5 审计工作存在重结果轻过程问题}

在实际审计中, 建设单位只重视外部审计, 却不重视内部审计, 也就是只重视审计结果, 却不重视审计过程, 这 给工程造价带来了严重影响。企业内部审计过程的缺失直接影响着审计工作的质量, 更影响着工程造价的质量 ${ }^{[4]}$ 。

\section{6 工程造价管理制度建设滞后}

当前我国建筑工程在工程造价管理制度上所表现出来的滞后性已经成为行业内涵式转型发展的重要制约因素, 首 先重视程度不足, 制度建设缺乏发展性。由于部分单位和个人的认知缺陷, 表面重视, 但是实际创新能力不够, 使得 在具体的制度建设上缺乏科学性、可操作性。其次制度滞后不仅仅表现为整体社会层面的管理监管体制的问题, 同样 也表现为企业层面内部管理制度落后的问题上 ${ }^{[5]}$ 。

\section{3 决策阶段的工程造价控制与管理}

对建筑工程项目的建造施工的相关决定是对工程项目的投资计划以及投资方面进行的选择和决策的过程, 同时还 必须要结合行业的发展实际以及行业未来的发展趋势, 对于建筑工程项目的投资的可行性和必要性的进行深入的分析 和研究, 并且对各种建筑工程项目的施工方案和计划进行技术上的、经济上的比较和研究。对建筑工程项目的相关施 工决策对工程项目的总体成本和工程项目完成后的经济效益有一个更清楚的认识和了解。当然这就要求工程项目的相 关成本管理和控制的数据信息必须要精准可靠，这是做好决策阶段的决策科学性和合理性的必要基础和前提。

\section{4 探讨加强建筑工程造价管理与控制对策}

\section{1 转变对造价管理的思维观念}

为了加快建筑工程项目的施工成本和费用管理控制的能力提升, 促进建筑工程项目的工程量的清单计价的模式在工 程项目的成本管理当中的应用, 首先相关企业的管理人员必须结合建筑行业当前的发展实际, 有效的改变传统的工程项 目的成本管理思维以及管理的模式, 朝着现代化的管理思想和管理体系当中进行转变和创新。一方面, 管理人员需要进 一步对现代的管理概念有一个清醒的认识, 另一方面, 需要结合工程项目的实际情况, 有针对性的对相关的而管理理念 和光甲进行完善和丰富, 确保建筑工程项目的成本的控制, 以及工程项目的建设可以获得合理的预期经济利润。

\section{2 加强对工程造价的管理与控制}

首先, 要想做好对建筑工程项目的施工成本的控制和管理, 首先我们必须在施工的计划方案的决策阶段进行的科 学合理、系统准确的工程项目的投资评估工作, 并有效的提高对建筑工程项目的施工建设的可行性进行严谨的论证。 此外需要结合各类专家学者的意见, 采取有效的手段对工程项目的施工成本进行严格的管理和控制, 以提高建筑工程 项目的资金的利用效率, 采用高效的施工方案和计划, 不仅能够提高工程项目的施工效率而且还可以缩短整个工程项 目的建造施工的周期, 进一步的降低了成本费用 ${ }^{[6]}$ 。

\section{3 构建统一的计价依据和计价方法}

当前在工程项目的施工建造的过程当中已经产生了以工程量为基础的工程计价的新的方式, 并且获得了非常广泛的应用和 普及, 这比过去的那种定额的工程计价的方式有更多的积极意义和现实好处。不仅降低了工程项目的总体造价, 而且还可以减 少了建筑工程项目的施工环节对于建筑材料的损耗和浪费, 减少了对环境的污染, 提高了建筑工程项目的施工环节的经济效益 以及生态环保的效益。而且能够降低工程项目的施工成本, 提高了工程项目的建造收益, 对于企业的发展来说也是很重要的。 


\section{4 加强对人才的培养}

建筑工程项目的成本管理工作是比较复杂和艰巨的一项任务, 直接影响到了建筑工程项目的施工成本以及经济效益。 因此, 这对工程项目的造价成本管理的工作人员也提出了很高的标准和要求。在这种情况下, 每个建筑工程项目的建造 施工都必须要有一个专业化的造价成本的管理团队, 必须做出高水平、高质量的施工成本管理和控制, 也需要保障相关 的工作人员具备较强的专业素质和综合能力以及高度的工作责任感。但是, 由于当前的建筑工程项目的开展是非常的频 繁的, 所以说对于这种高技术能力和水平的工程管理专业人员目前来说是非常紧缺的, 应该从根本上加快相关造价管理 的人才的培养速度。建筑工程的相关造价管理部门可以与先进的、高水平的教育培训机构开展委托培训的合作, 为了更 好的提高企业的成本管理工作人员的职业技能的教育和培训, 并且充分的结合相关领域的最新理论成果的教育以及实践 方面的培养，以充分的提高成本管理的工作人员的专业能力和实践水平，提高企业的成本管理的质量。

\section{5 优化和完善预算编制}

实践中如果业务相对比较稳定, 则可选择固定预算编制; 若业务相对较多, 则应当以滚动式预算编制为宜。与此 同时, 编制工作也应当保持与时俱进, 顺应发展要求, 不断优化和改进, 切忌一味地沿用传统的方式和方法而止步不 前。需要强调的是预算编制应当在连续性以及完整性基础上结合新内容, 对基本问题进行妥善解决, 取长补短。预结 算编制过程中, 应当不断的优化和改进方式方法, 确保编制文件的科学合理性, 减少工作量, 以此来有效促进工程造 价管理实效。

\section{结束语}

综上所述, 建筑工程造价管理过程中, 预结算编制的专业性非常的强, 实践中我们应当立足拟建工程项目实际情 况, 积极开展工程造价管理工作。同时, 还要完善和健全现有的工程造价管理制度, 加大工程造价管理力度, 从人员 素质提升、制度完善等方面着手，提高工程造价管理效率。

\section{[参考文献]}

[1]张金亮. 关于建筑工程造价控制与管理分析探讨 [J]. 商讯, 2020 (12) : 143-144.

[2] 毕京晴. 关于建筑工程造价控制与管理分析探讨 [J]. 居舍, 2020 (05): 132.

[3] 戴虹. 关于建筑工程造价控制与管理分析探讨 [J]. 现代物业 (中旬刊), 2019 (09) : 127.

[4] 崔志荣. 关于建筑工程造价控制与管理分析 [J]. 建材与装饰, 2019 (26) : 136-137.

[5]苑红英. 基于建筑工程造价控制管理的有效分析研讨 [J]. 智能城市, 2019, 5(14): 117-118.

[6]王静.建筑工程造价控制与管理分析 $[J]$. 居舍, 2019(19): 143.

作者简介: 王启金 (1971-), 男, 云南省玉溪市红塔区, 汉族, 大专学历, 工作方向为工程造价。 